\title{
Construction in the digital economy: prospects and areas of transformation
}

\author{
Vadim Kankhva ${ }^{1}$, Yana Andryunina ${ }^{2,}$, Svetlana Belyaeva ${ }^{2}$, and Yaroslav Sonin ${ }^{2}$ \\ ${ }^{1}$ Moscow State University of Civil Engineering, 26, Yaroslavskoe shosse, Moscow, 129337, Russia \\ ${ }^{2}$ Voronezh State Technical University, Moscow Avenue, 14, Voronezh, 394026, Russia
}

\begin{abstract}
The authors substantiated the need for digitalization of construction as an imperative of embedding the industry in the ecosystem of the digital economy, taking into account the implementation of the principle of fractality in management. The main digitalization tools have been identified, points of growth in various projections have been determined, and the impact of factors-drivers of digital transformation has been analyzed and assessed. In the process of digitalization of the construction industry, it is necessary, first of all, to ensure the integration of information models of investment and construction projects and existing state information systems. The paper considers the process of integrating the FSIS PC and the BIM design system, identifying the corresponding problem areas and the main stakeholders in the creation of an information system of pricing in construction, and differentiating the possible effects.
\end{abstract}

\section{Introduction}

The digital economy is a highly competitive form of economic organization and contributes to the growth of globalization and networkization due to the use of information and communication technologies that have a cross-border nature. Nowadays, there is no single generally accepted definition of the digital economy. However, it should be noted that the digital economy is not so much a collection of information and communication technologies as new methods of data management and decision-making that facilitate quick response and adaptation to changing environmental conditions, including risk-forming factors. The development of the digital economy and the digitalization of the construction and utilities sectors at the state level are caused by the adoption of the Information Society Development Strategy for 2017-2030 and the state program "Digital Economy of the Russian Federation" in 2017 [1].

The progressive development of the construction industry in modern conditions is impossible without embedding it, as well as the processes of creating products it produces, into the ecosystem of the digital economy of the Russian Federation, which will contribute not only to the sustainable innovative development of the industry and the enterprises operating in it, but also to create favorable conditions for doing business and improving the quality of the urban environment by improving the quality characteristics of capital construction objects being built.

\footnotetext{
${ }^{*}$ Corresponding author: jarogacheva@mail.ru
} 
Embedding construction in the ecosystem of the digital economy is impossible without the digitalization of the industry, which should follow the path of accelerated implementation of IT technologies in the design and construction process, as well as the creation of a unified information environment for construction, uniting all existing information systems, optimizing their activities regarding the collection and analysis of information in the field of construction, process automation.

We believe that information modeling acts as the basis for the digitalization of construction, which provides the possibility of constant control over the implementation of investment and construction projects, as well as over the operation and overhaul of existing facilities and urban management.

\section{Materials and Methods}

The level of digitalization of the construction industry in Russia, as well as in the world, is quite low.

The driver of the digital transformation of construction in the world is BIM technologies [2], as well as Internet of Things technologies used at the objects of construction and utility services. The use of information and communication technologies and software for managing business processes of both projects and industry enterprises should be highlighted as the main areas for the development of digitalization of construction; computer-aided design technologies for buildings and structures, information modeling technologies, machine learning, augmented reality, the Internet of Things. Cloud-based data management platforms are also widely developed. Pilot projects on the use of additive technologies in construction are being implemented.

The digitalization of construction and utility services in the Russian Federation is also supported at the level of state and sectoral management through the adoption of appropriate regulatory documents [3] and the implementation of the Smart City project. Also, federal state information systems (FSIS) are being created, containing information necessary for both construction and utility services (FSIS PC, SIS HCS, SISUPA, FSIS USRT, SISI, SIS FEC, FSIS TP, KIRS SBDGI, FSIS “ARSHIN", etc.). However, the large number, fragmentation of systems, the complexity of import and export of data from one FSIS to another make their application in practice difficult and often inappropriate.

However, the most frequent use is characteristic precisely for information systems, as well as for information modeling technologies used in the design of buildings and structures. For the development and wider application of information modeling, it is necessary to create appropriate classifiers and information systems. It should be noted that a fairly large part of the rule-making work has already been implemented and includes the adoption of a number of standards and regulatory and methodological documents. Also, amendments have been made to the Urban Planning Code, including the official consolidation of the concepts of the building information classifier and information model.

Of course, it is absolutely inappropriate to use information modeling in the design and construction of all objects. However, the implementation of information modeling helps to reduce the number of collisions detected during construction, and also optimizes the technological process of managing objects at the operation stage [4].

In the Russian Federation, despite the existing growth in the number of organizations using information modeling, the level of use of this technology is quite low today (Fig. 1). 


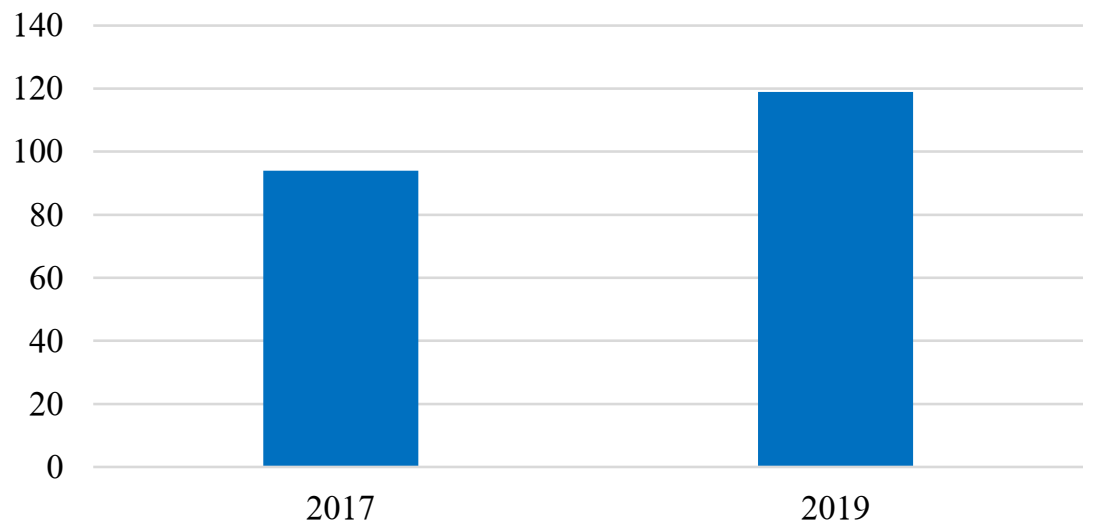

- Respondents using information modeling technologies in their activities

Fig. 1. Application of information modeling technologies in the Russian Federation (compiled on the basis of [5-6])

The use of automation in design will allow, among other things, to implement the idea of digitalization of cost engineering in construction. Today, one of the main problems of pricing in construction can be called the use of the base-index pricing method, which made it possible to create a clear methodology for determining the cost of construction in a stable economic situation and the practical absence of inflationary processes. In other conditions, assuming a constant dynamics of the cost of resources, the resource method is the most applicable and more accurate. Besides, it should be noted that the calculation of estimates by the base-index method today, in 2020, is based on the application of the 2001 base standards and the corresponding value change indices, which do not correspond to modern realities and needs. Therefore, at all levels of management, including the position of the Ministry of Construction and Housing and Utilities, a movement towards the use of the resource pricing method is postulated [7].

An accurate calculation of the construction cost based on the current prices of the required resources is in demand by three main categories of stakeholders. The first category includes manufacturers of building materials, product designs with the goal of increasing sales of manufactured products, avoiding overstocking in warehouses, and meeting existing market demand. We consider it necessary to include cost engineers and designers in the second category of stakeholders, whose goal is to reduce labor costs and time costs for drawing up estimates using the resource method, for which it is necessary not only to draw up a specification of equipment and building materials used in the project, but also to form requests and the corresponding analytics of commercial proposals available in the region for each of the necessary resources. The third category of stakeholders is construction customers, whose goal is not only to get the effect of increasing the accuracy of estimated calculations, but also the ability to promptly account for making certain changes to the project in the construction budget. The use of neural networks to search and process information about suppliers of construction resources and the corresponding cost of these resources will reduce the time required to search and analyze information, which will lead to ensuring the rhythm of production, increasing the accuracy of scheduling and corresponding economic calculations, as well as reducing storage costs due to clearer planning logistics with the ability to supply materials, structures and products directly to the on-site warehouse of the construction site. Engineers and designers will be able to quickly generate specifications in 
$\mathrm{CAD}$ and receive information on the availability of materials and average prices for them in the construction region. At the same time, suppliers will be able to quickly sell their products and deliver objective and timely information to consumers about the price and availability of certain building materials and products.

A similar idea within the ecosystem of the digital economy has transformed into the creation of the Federal State Information System for Pricing in Construction (FSIS PC). This information system is designed to collect information on the current cost of resources for construction and to create general access to this information for all stakeholders. The creation of the FSIS PC and its actual functioning will make it possible to implement the transition to the resource pricing method in an interactive mode by linking the above-mentioned information system both with the estimated programs and with design automation systems, with construction planning systems and construction control and cost audit of the investment and construction projects being implemented [8].

The organizational scheme of digitalization in the development and implementation of the investment and construction project is shown in Figure 2. The effects and costs of the corresponding processes are also determined there.

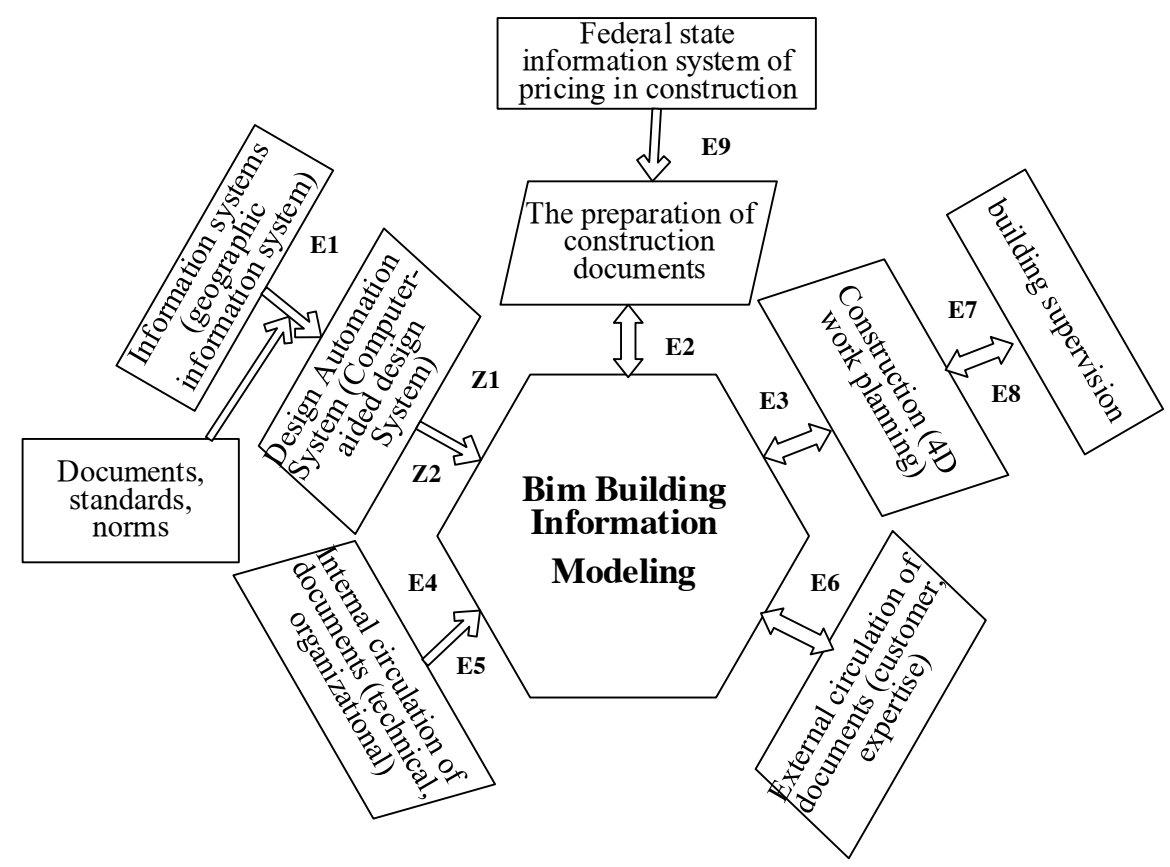

Fig. 2. Organizational scheme of digitalization of the processes of implementation of an investment and construction project, taking into account the integration with the FSIS PC, where: E1 - the effect of compliance with the norms, including reducing the time for approvals, checks, etc.; E2 - the effect of increasing the accuracy of estimated calculations; E3 - the effect of reducing the number of collisions, both spatial and temporal ones; E4 - reduction of transaction costs associated with document flow and performance discipline; E5 - the effect of reducing the number of changes required at the initiative of the customer; E6 - the effect of reducing the number of comments from the examination authorities; E7 - reduction in the number of comments based on the results of construction supervision (corresponding reduction in the cost of correcting comments); E8 - reduction of transaction costs for communications; E9 - cost reduction through the use of resource pricing method and analytics of market prices of resources; Z1 - cost growth (for outsourcing - for transition into an information model, for information modeling on its own - for the purchase of software products, training and transition to a new design system); Z2 - the increase in the cost of integrating the BIM model. 
Based on the deterministic effects and costs of the corresponding digitalization processes, we consider it necessary to apply not only the criteria of financial efficiency, but also to take into account the industrial or social effect when carrying out a calculation substantiation of efficiency [9].

\section{Results}

Based on the results of literature analysis, surveys of specialists of construction organizations, modeling of effects, "points of growth" of digitalization of construction and utility services at the meso- and micro-level of management in the projection of innovative technologies are information modeling and the formation of information systems, in the regional projection Moscow and St. Petersburg [6]; in the projection of subject specificity - individual innovatively active enterprises and organizations, as well as enterprises cooperating with foreign partners; in the projection of types of construction - organizations and enterprises implementing investment and construction projects in the nuclear energy industry.

Points of growth characterize the potential for the development of the digitalization process in the industry. It should be noted that the presence of local growth points is characterized only by sectoral influence and needs initiated development [10]. The intersectoral influence of growth points is impossible without the creation and activation of multi-level network connections created by development drivers.

For further analysis, factors - development drivers were identified, grouped relative to the goal of digitalization in accordance with the concept of systemic competitiveness. To assess the degree of influence of each of the groups of factors, firstly, rank values were obtained:

RANK $=\%$ of those who chose this factor * place in the rating (weighted score).

Further, the rank indicators were normalized, i.e. are given in a comparable form in the range $[0,1]$. The next step was to obtain the group total normalized values using the following calculation formula:

$$
R_{g r}=\sum_{g r} \frac{F_{n} * m_{n}}{\sum_{b} F_{n} * m_{n}} 100
$$

where $\mathrm{R}_{\mathrm{gr}}$ - significance of a group of factors; $\mathrm{F}_{\mathrm{n}}$ - significance of factor " $\mathrm{n}$ "; $\mathrm{m}_{\mathrm{n}}$ - the place of the factor, the weighting coefficient of significance " $\mathrm{n}$ ".

Table 1 shows the indicators of the significance of each of the groups of driver factors.

Table 1. Drivers of digitalization of construction in the projection of groups of factors, points.

\begin{tabular}{|c|l|c|}
\hline Group of factors & \multicolumn{1}{|c|}{ Driver factors } & $\begin{array}{c}\text { Significance, } \\
\text { in points }\end{array}$ \\
\hline Institutional & $\begin{array}{l}\text { Creation and application of a unified information system } \\
\text { in construction and HCS }\end{array}$ & 23 \\
\cline { 2 - 2 } & $\begin{array}{l}\text { Development and formal adoption of resource } \\
\text { classification }\end{array}$ & \\
\cline { 2 - 2 } & $\begin{array}{l}\text { Securing the possibility of using the BIM model in the } \\
\text { examination of ICP }\end{array}$ & \\
\cline { 2 - 2 } & Refinement of BIM standards \\
\cline { 2 - 2 } & $\begin{array}{l}\text { Introduction of BIM study into educational and } \\
\text { professional standards in construction }\end{array}$ & \\
\cline { 2 - 3 } & $\begin{array}{l}\text { Adoption of regulatory documents on digitalization of } \\
\text { construction and HCS }\end{array}$ & \\
\cline { 2 - 3 } & Growth in payments for construction control and audit \\
\cline { 2 - 3 } & Mandatory information modeling for large projects & \\
\cline { 2 - 2 } & Change of NTD in construction \\
\hline
\end{tabular}




\begin{tabular}{|c|c|c|}
\hline Group of factors & Driver factors & $\begin{array}{l}\text { Significance, } \\
\text { in points }\end{array}$ \\
\hline & Development of a digital construction environment & \\
\hline \multirow[t]{3}{*}{ Innovative } & $\begin{array}{l}\text { Increasing innovation activity in construction and } \\
\text { related industries }\end{array}$ & \multirow[t]{3}{*}{21} \\
\hline & $\begin{array}{l}\text { Development of technology for the operation of digital } \\
\text { platforms and digital construction environment }\end{array}$ & \\
\hline & OpenBIM development & \\
\hline \multirow[t]{4}{*}{ Economic } & Reducing the cost of software and specialist services & \multirow[t]{4}{*}{19} \\
\hline & Reducing construction costs & \\
\hline & Subsidizing digital construction projects & \\
\hline & Reducing administrative barriers & \\
\hline \multirow[t]{2}{*}{ Information } & Rising technology awareness & \multirow[t]{2}{*}{20} \\
\hline & $\begin{array}{l}\text { Development of information and communication } \\
\text { technologies }\end{array}$ & \\
\hline Infrastructure & $\begin{array}{l}\text { Availability of infrastructure for interaction in the } \\
\text { implementation of ISP based on digital technologies }\end{array}$ & 17 \\
\hline
\end{tabular}

The analysis allows concluding that the dominant influence of the institutional environment on the development of construction digitalization processes continues the trend identified by other researchers $[8,11]$ and confirms the hypothesis that in modern conditions, the digital transformation of construction is impossible without an institutional framework and a developed institutional environment.

Besides, information factors become the key drivers of the construction digitalization process, in addition to economic ones, which reflects the conditions of the modern digital economy.

\section{Discussions}

The need to resolve a large number of issues and process a large amount of information makes it necessary to digitize the processes of implementing an investment and construction project, which becomes possible with the justified use of information modeling, taking into account the existing state information systems.

It should be noted that in countries that fully use information modeling in the design of facilities for a long time, the corresponding reference information on the actual cost of resources is accumulated based on the results of implemented projects in the databases of information systems for use in assessing the cost of new projects [12]. With the construction pricing system existing today in Russia, this approach, especially when working with a state or municipal order, is almost inapplicable due to the operation of a system of estimated standards based on state elementary estimated standards. To use the integration of BIM technology and the information system of pricing in construction, it is necessary, firstly, to develop a classification system for building resources, compatible with the world ISO120062, used for information modeling, including the classifier developed for FSIS PC. Secondly, to ensure the final filling of the FSIS PC with relevant information along with the development of standards for indirect and other costs and the procedure for their application when using the current FSIS PC prices. Thirdly, to develop a mechanism for the formation of estimated prices for each stage of the project from the pre-project to the stage of working documentation and ensure their integration with the price information of the FSIS PC.

In addition, it is necessary to ensure the compliance of the proposed design solutions with the requirements of current norms and standards, their inclusion in the estimate documentation, ensure the necessary approvals and organize the workflow. Accordingly, there is a need to digitize the relevant business processes. At the same time, proceeding from 
the thesis about the need to eliminate collisions, we consider it expedient, especially with the design documentation already developed in $2 \mathrm{D}$, to transfer it into an information model format with the interconnection of all business processes.

\section{Conclusion}

The overall goal of digitalization of construction and utility services is the formation and development of a digital environment for managing the life cycle of facilities in order to improve the quality of physical capital for the well-being of future generations within the framework of the concept of sustainability. Accordingly, the digitalization of construction implies an increase in the level of innovation in investment and construction activities. To achieve the target of digitalization of construction and utility services, it is necessary to change the management principles throughout the entire life cycle of an object by introducing flexible management of resources, processes and communications based on information exchange.

The above postulate is valid not only at the level of management of construction objects or investment and construction projects, but also at the level of a construction company and industry. This hierarchical relationship is based on the existence of the principle of fractality.

The above conclusions indicate the possibility and feasibility of applying the conclusions and recommendations of the authors at all levels of the construction industry hierarchy, i.e. for managing investment projects, enterprises and industry.

\section{References}

1. S. A. Tinkov, E. V. Tinkova, Indicator to Assess the Level of Development of Productive Capacity and Quality of Life. In: Solovev D. (eds) Smart Technologies and Innovations in Design for Control of Technological Processes and Objects: Economy and Production. FarEastCon 2018. Smart Innovation, Systems and Technologies, Springer, Cham., 139 (2019) https://doi.org/10.1007/978-3-030-18553-4_69

2. K. E. Kovalenko, S. Y. Bakhvalov, A. O. Zekiy, V. V. Vikulina, S. A. Tinkov, T. V. Tkacheva, Key indicators of innovation activity of Russia (from 2011 to 2017), Journal of Entrepreneurship Education, 22(3), 1-7 (2019)

3. O. V. Konina, S. A. Tinkov, E. V. Tinkova, Management in Higher Education Based on "Smart Technologies": Digital Managerial Staff vs. Artificial Intelligence. Lecture Notes in Networks and Systems, 155, 1738-1745 (2021)

4. S. S. Uvarova, Kh. Gumba, E. Kiseleva, Ya. Sonin, E3S Web of Conferences. XIII International Scientific and Practical Conference "State and Prospects for the Development of Agribusiness INTERAGROMASH 2020", 11004 (2020)

5. Otchet «Ocenka primeneniya BIM-tekhnologij v stroitel'stve. Rezul'taty issledovaniya effektivnosti primeneniya BIM-tekhnologij $\mathrm{v}$ investicionno-stroitel'nyh proektah rossijskih kompanij» http://nopriz.ru/upload/iblock/2cc/4.7_bim_rf_otchot.pdf (Last accessed 10.12.2020)

6. Otchet po issledovaniyu «Uroven' primeneniya BIM V Rossii 2019» http://concurator.ru/information/bim_report_2019/?fbclid=IwAR2OVYWwWqYXgN A C8MJeyNK_kg--bboku_TyYuRwefgj4OQ7LAvM-EeQC8Y (Last accessed 20.12.2020)

7. Ya. L. Sonin, K. S. SHul'gina, Aktual'nye voprosy ekonomiki. Sbornik statej III Mezhdunarodnoj nauchno-prakticheskoj konferencii, 237-241 (2020) 
8. Ya. Rogacheva, A. Panenkov, Z. Petrikova, E. Nezhnikova, E3S Web of Conferences, 03037 (2018)

9. A. Kogan, Global Journal of Pure and Applied Mathematics (GJPAM), 12(1), 19-32 (2016)

10. S. Uvarova, A. Bukreev, V. Vlasenko, MATEC Web of Conferences, 05044 (2018)

11. N. Sirotkina, M. Meshcheryakova, E. Syshchikova, M. Filatova, A. Greshonkov Proceedings of the 33rd International Business Information Management Association Conference, IBIMA 2019: Education Excellence and Innovation Management through Vision 2020 Education Excellence and Innovation Management through Vision 2020, 33, 8970-8975 (2019)

12. R. Miettinen, Beyond the BIM utopia: Approaches to the development and implementation of building information modeling https://doi.org/10.1016/j.autcon.2014.03.009 